\title{
Do we need antibiotic prophylaxis in endoscopic inguinal hernia repair? Results of the Herniamed Registry
}

\author{
F. Köckerling ${ }^{1} \cdot$ R. Bittner ${ }^{2} \cdot$ D. Jacob ${ }^{1}$ - C. Schug-Pass ${ }^{1}$ - C. Laurenz ${ }^{1}$ \\ D. Adolf ${ }^{3} \cdot$ T. Keller ${ }^{3} \cdot$ B. Stechemesser ${ }^{4}$
}

Received: 6 October 2014/ Accepted: 6 February 2015/Published online: 19 March 2015

(C) The Author(s) 2015. This article is published with open access at Springerlink.com

\begin{abstract}
Introduction The use of antibiotic prophylaxis in inguinal hernia repair is a controversial issue. Accepted randomized controlled trials or registry data with specific analysis of endoscopic repaired patients do not exist.

Patient and methods The data presented in this study compared the prospectively collected data from the Herniamed Registry on all patients who had undergone unilateral, bilateral or recurrent repair of inguinal hernias using either endoscopic or open techniques between September 1, 2009, and March 5, 2014. In total, 85,033 patients were enrolled. Of these patients, 48,201 (56.7\%) had an endoscopic and 36,832 (43.3\%) an open repair. The target variables analyzed were impaired wound healing and deep infections with mesh involvement within 30 days after the operation.

Results Analysis of the patient group with endoscopic/ laparoscopic inguinal hernia repair $(n=48,201)$ did not identify any significant influence of antibiotic prophylaxis on postoperative impaired wound healing, which occurred in 53 cases $(p=0.6431)$. Nor was it possible to identify
\end{abstract}

F. Köckerling

ferdinand.koeckerling@vivantes.de

1 Department of Surgery and Center for Minimally Invasive Surgery, Academic Teaching Hospital of Charité Medical School, Vivantes Hospital, Neue Bergstraße 6, 13585 Berlin, Germany

2 Winghofer Medicum, Hernia Center, Winghofer Straße 42, 72108 Rottenburg am Neckar, Germany

3 StatConsult GmbH, Halberstädter Straße 40 a, 39112 Magdeburg, Germany

4 Hernia Center Cologne, PAN - Hospital, Zeppelinstraße 1, 50667 Cologne, Germany any significant impact of antibiotic prophylaxis on the deep infections seen in 27 cases $(p=0.8409)$. Analysis of the open inguinal hernia repair group revealed that, unlike the laparoscopic/endoscopic group, antibiotic prophylaxis had a significant impact on the postoperative impaired wound healing and deep infection rates. The risk of postoperative impaired wound healing with antibiotic prophylaxis was significantly lower [OR $0.677(0.479 ; 0.958), p=0.027$ ]. Conclusion The positive impact of the endoscopic/laparoscopic technique on avoidance of impaired wound healing and deep infections with mesh involvement is already so great that antibiotic prophylaxis has no additional benefit. In contrast, antibiotic prophylaxis should be administered for open inguinal hernia repair.

Keywords Antibiotic prophylaxis - Endoscopic inguinal hernia repair - TAPP - TEP - Postoperative complications . Wound infection

The use of antibiotic prophylaxis in inguinal hernia surgical repair is a controversial issue. Prospective randomized controlled trials (RCTs) have identified postoperative infection rates (impaired wound healing, mesh infections) of between 0 and $8.9 \%$ in the absence of antibiotic prophylaxis and of between 0 and $8.8 \%$ on administration of antibiotic prophylaxis [1].

Of the 14 RCTs that compared inguinal hernia repair while using antibiotic prophylaxis versus placebo, 13 surgical procedures were performed using open repair and only one with an endoscopic technique [1].

That single RCT involving endoscopic inguinal hernia repair has incorrect randomization, lacks a definition of wound infection and is heavily underpowered with only 40 patients in each arm. It does not allow any conclusion to be made and is not included in the Cochrane review [1]. 
In a large case series with 8050 TAPP operations carried out for 6479 patients who had received antibiotic prophylaxis, the wound infection rate was $0 \%$ and the mesh infection rate $0.1 \%$ [2].

In a large case series with 5203 TEP operations involving 3868 patients who had received antibiotic prophylaxis, the wound infection rate was $0.08 \%$ and the mesh infection rate $0.02 \%$ [3].

The Swedish National Inguinal Hernia Registry recorded wound infection and mesh infection rates between 1992 and 2006. The incidence was $1.4 \%$ in 28,220 patients registered as having received antibiotic prophylaxis. The infection rate was also $1.4 \%$ in the non-prophylactic group, consisting of 104,354 patients. There was no specific analysis of the laparoscopic patients representing approximately $8 \%$ of patients [1].

We now analyze below data from the Herniamed Registry to explore the influence that the use of an endoscopic technique for repair of inguinal hernia had on the rate of impaired wound healing and on deep infections with mesh involvement compared with open surgery. We will then also endeavor to elucidate whether administration of antibiotic prophylaxis further reduced the impaired wound healing and mesh infection rates.

\section{Patients and methods}

The Herniamed quality assurance study is a multicenter, internet-based hernia registry into which 383 participating hospitals and surgeons in private practice in Germany, Austria and Switzerland (status: March 5, 2014) had entered data prospectively on their patients who had undergone hernia surgery [5].

The analysis now presented here compared the prospectively collected data on all patients who had undergone unilateral, bilateral or recurrent repair of inguinal hernia using either endoscopic or open techniques between September 1, 2009, and March 5, 2014. Inclusion criteria were minimum age of 16 years, primary or recurrent inguinal hernia and elective or emergency unilateral or bilateral inguinal hernia repair. In total, 85,033 patients were enrolled. Of these patients, 48,201 (56.7\%) had an endoscopic and 36,832 (43.3\%) an open repair. The data on these endoscopic inguinal hernia operations recorded in the Herniamed Registry originated from 315 out of 383 participating institutions.

The target variables analyzed were impaired wound healing and deep infections with mesh involvement within 30 days after the operation. The potential influence variables include, apart from the surgical technique and antibiotic prophylaxis, the patient's age (years), sex $(\mathrm{m} / \mathrm{f})$, ASA status (I-IV), primary operation versus recurrent repair, hernia defect size (EHS Grade I-III) and general risk factors (nicotine, COPD, diabetes, cortisone, immunosuppression, etc.).

All analyses were performed with the software SAS 9.2 (SAS Institute Inc., Cary, NY, USA) and intentionally calculated to a full significance level of $5 \%$, i.e., they were not corrected in respect of multiple tests, and each $p$ value $\leq 0.05$ represents a significant result.

Since these data refer to unilateral as well as to bilateral operations, some of the variables used for analysis are given for both operated sides, but their values may differ. To ensure the independence of the sample elements used for analysis, the variables were aggregated as follows: In the case of a hernia defect size, the larger of the two defects was chosen and a postoperative infectious complication was considered to be present if at least one of the two sides experienced such a complication.

For unadjusted analyses of antibiotic influence on categorical outcome parameters, Fisher's exact test was used. In case of more than two categories, exact analyses were not possible. Here, the asymptotic Chi-square test was used. Unadjusted analyses of continuous normal distributed outcome variables were realized using the robust $t$ test (Satterthwaite).

Mainly, influences of antibiotic treatment and further confounding effects of patient characteristics were simultaneously reviewed in multivariable analyses. Potentially influencing factors were as follows: operating method (endoscopic/conventional), age (years), sex (male/female), ASA score (I-IV), defect size (EHS I-III), risk factors (nicotine, COPD, diabetes mellitus, aorta aneurysm, immunosuppression, cortisone, impaired coagulation, ASS/ Plavix, Marcumar) and primary operation (yes/no). Risk factors were dichotomized, i.e., 'yes' if at least one risk factor is positive and 'no' otherwise.

Estimates for odds ratio (OR) and the corresponding $95 \%$ confidence interval were given. For age [years], the 10-year OR estimate was given.

Since the properties of endoscopic and conventional techniques are presumably different, further analyses are made in these subgroups.

\section{Results}

Between September 1, 2009, and March 5, 2014, $n=85,033$ inguinal hernia operations were recorded in the Herniamed Registry in accordance with the inclusion criteria. Antibiotic prophylaxis was administered in $n=60,831$ cases $(71.54 \%)$ and was not in 24,202 cases $(28.46 \%)$. Of the 60,831 cases that had received antibiotic prophylaxis, $n=59,177(97.27 \%)$ received single-shot antibiotic prophylaxis, $n=253(0.42 \%)$ for 1 day, $n=607(0.99 \%)$ for 
2-3 days, and $n=794(1.31 \%)$ received antibiotic treatment for more than 3 days. No details of the antibiotic used were recorded in the registry study. Based on the recommendations of the German Paul-Ehrlich Society, in general ampicillin with a beta-lactamase inhibitor or a group 1 or 2 cephalosporin was administered [6]. As regards the surgical techniques employed for the analyzed patients, in the endoscopic group this was TAPP in $n=29,775$ of cases (35\%) and TEP in $n=18,426$ of cases (21.7 \%), which thus accounted for $56.7 \%$ of endoscopic procedures. In the open inguinal hernia repair group, Lichtenstein operation was performed in $n=23,820$ of cases (28.0\%), Shouldice operation in $n=3057(3.6 \%)$, plug and patch technique in $n=3623(4.3 \%)$, Gilbert technique in $n=2554$ (3.0\%) and TIPP technique in $n=1675(2.0 \%)$. Other techniques were used for $n=2103(2.4 \%)$.

\section{Unadjusted analyses}

Analysis of the unadjusted correlation between antibiotic prophylaxis and the patient characteristics' and operating technique variables demonstrated that there were highly significant differences across all variables between the patients who had and had not received antibiotic prophylaxis (in each case $p<0.001$ ). For example, more laparoscopic/endoscopic operations were conducted while using antibiotic prophylaxis. Besides, the proportion of patients with risk factors and recurrences who had received antibiotic prophylaxis was significantly higher. The same was true for male gender and ASA classification. For low ASA status, antibiotic prophylaxis was rarely administered, with that applying also for smaller hernia defect sizes. Finally, patients who received antibiotic prophylaxis were on average just below 3 years older (Table 1).

Unadjusted analysis of the outcome variables revealed that in the patient group that had received antibiotic prophylaxis, significantly fewer cases of impaired wound healing occurred compared with the patient group that had not received antibiotic prophylaxis $(0.20$ vs $0.30 \% ; p=0$ 0.009). Likewise, on using antibiotic prophylaxis, there were significantly fewer cases of deep infections with mesh involvement (0.12 vs $0.20 \% ; p=0.006)$ (Table 2$)$.

\section{Multivariable analysis of the total patient collective}

The postoperative impaired wound healing rates were significantly influenced by antibiotic prophylaxis, surgical technique, sex, ASA classification and primary operations/ recurrent repairs. Here antibiotic prophylaxis had a preventive effect on impaired wound healing [OR 0.706 (0.525; 0.949), $p=0.021$ ], as did conduct of laparoscopic/ endoscopic operation [OR $0.318(0.230 ; 0.439), p<$ 0.001]. Likewise, there were significantly fewer cases of postoperative impaired wound healing among men [OR $0.531(0.369 ; 0.764), p<0.001]$ as well as for primary hernias [OR $0.601(0.412 ; 0.876), p=0.008]$. The negative influence of the ASA status was imputed especially to the increased impaired wound healing rates observed for ASA IV status [IV vs I: OR $4.226(1.579 ; 11.311) p=$ 0.001] (Table 3).

Postoperative deep infection with mesh involvement was affected by antibiotic prophylaxis, surgical technique and ASA classification. An OR of 0.593 (0.408; 0.862), $p=0.006$, was calculated for antibiotic prophylaxis. The risk of postoperative deep infection was significantly lower for the laparoscopic/endoscopic surgical technique [OR $0.259(0.167 ; 0.402), p<0.001]$. Deep infections also occurred significantly more often among ASA IV patients [IV vs I: OR 5.425 (1.732; 16.992), $p=0.008$ ] (Table 4).

In summary, it can be concluded that impaired wound healing and deep infections occurred significantly less often after endoscopic/laparoscopic inguinal hernia surgery compared with open repair. In the total patient collective comprising $n=48,201$ endoscopic/laparoscopic and $n=$ 36,832 open inguinal hernia operations, antibiotic prophylaxis significantly reduced impaired wound healing and deep infection rates.

\section{Multivariable analysis of laparoscopic/endoscopic inguinal hernia operations}

Analysis of the patient group with endoscopic/laparoscopic inguinal hernia repair $(n=48,201)$ did not identify any significant influence exerted by the different variables on postoperative impaired wound healing, which occurred in 53 cases $(p=0.6431)$. Nor was it possible to identify any significant impact of the variables on the deep infections seen in 27 cases $(p=0.8409)$ (Table 5).

\section{Multivariable analysis of open inguinal hernia operations}

Analysis of the open inguinal hernia repair group revealed that, unlike the laparoscopic/endoscopic group, antibiotic prophylaxis had a significant impact on the postoperative impaired wound healing and deep infection rates. The risk of postoperative impaired wound healing with antibiotic prophylaxis was significantly lower [OR 0.677 (0.479; 0.958 ), $p=0.027$ ] (Table 6). Given a total rate of $0.39 \%$, this would correspond to 31 cases of impaired wound healing for every 10,000 open repair operations performed under antibiotic prophylaxis and to 46 such complications for every 10,000 open repairs carried out without antibiotic prophylaxis. Likewise, the postoperative deep infection rate was found to be significantly reduced with antibiotic prophylaxis [OR $0.522(0.341 ; 0.798), p=0.003$ ] 
Table 1 Demographic and surgery-related parameters

\begin{tabular}{|c|c|c|c|}
\hline & Antibiotic prophylaxis & No antibiotic prophylaxis & $p$ value \\
\hline \multicolumn{4}{|c|}{ Demographic parameters } \\
\hline \multicolumn{4}{|l|}{ Age } \\
\hline Years $\pm \mathrm{SD}$ & $58.3 \pm 16.3$ & $55.6 \pm 16.8$ & $<0.001$ \\
\hline \multicolumn{4}{|l|}{ Sex } \\
\hline Male & $53,703(88.28 \%)$ & $21,141(87.35 \%)$ & \\
\hline Female & $7128(11.72 \%)$ & $3061(12.65 \%)$ & $<0.001$ \\
\hline \multicolumn{4}{|l|}{ ASA score } \\
\hline I & $19,188(31.54 \%)$ & $9,276(38.33 \%)$ & \\
\hline II & $31,028(51.01 \%)$ & $12,111(50.04 \%)$ & \\
\hline III & $10,300(16.93 \%)$ & $2740(11.32 \%)$ & \\
\hline IV & $315(0.52 \%)$ & $75(0.31 \%)$ & $<0.001$ \\
\hline \multicolumn{4}{|c|}{ Surgery-related parameters } \\
\hline \multicolumn{4}{|c|}{ Operation technique } \\
\hline Laparoscopic & $35,567(58.47 \%)$ & $12,634(52.20 \%)$ & \\
\hline Open & $25,264(41.53 \%)$ & $11,568(47.80 \%)$ & $<0.001$ \\
\hline \multicolumn{4}{|l|}{ Risk factors } \\
\hline Yes & $19,183(31.53 \%)$ & $6373(26.33 \%)$ & \\
\hline No & $41,648(68.47 \%)$ & $17,829(73.67 \%)$ & $<0.001$ \\
\hline \multicolumn{4}{|l|}{ Defect size } \\
\hline $\mathrm{I}(<1.5 \mathrm{~cm})$ & $9772(16.06 \%)$ & $4509(18.63 \%)$ & \\
\hline II $(1.5-3 \mathrm{~cm})$ & $35,381(58.16 \%)$ & $13,383(55.30 \%)$ & \\
\hline III $(>3 \mathrm{~cm})$ & $15,678(25.77 \%)$ & $6310(26.07 \%)$ & $<0.001$ \\
\hline \multicolumn{4}{|c|}{ Primary operation } \\
\hline Yes & $54,018(88.80 \%)$ & $21,833(90.21 \%)$ & \\
\hline No & $6813(11.20 \%)$ & $2369(9.79 \%)$ & $<0.001$ \\
\hline
\end{tabular}

\begin{tabular}{lccc}
\hline Unadjusted analysis & Antibiotic prophylaxis & No antibiotic prophylaxis & $p$ value \\
\hline $\begin{array}{l}\text { Postoperative complications } \\
\text { Impaired wound healing }\end{array}$ & & & \\
Yes & $123(0.20 \%)$ & $73(0.30 \%)$ & \\
No & $60,708(99.80 \%)$ & $24,129(99.70 \%)$ & 0.009 \\
Deep infection & $71(0.12 \%)$ & $48(0.20 \%)$ & \\
Yes & $60,760(99.88 \%)$ & $24,154(99.80 \%)$ & 0.006 \\
No & & & \\
\hline
\end{tabular}

Table 2 Postoperative complication rates of impaired wound healing and deep infection surgery. Besides, other risk factors were identified for onset of impaired wound healing and deep infections with mesh involvement. This also applies for patients with risk factors. For the total patient collective comprising 85,033 patients with 48,201 endoscopic/laparoscopic and 36,832 open inguinal hernia operations, it was revealed that postoperative infectious complications were significantly reduced by use of the endoscopic/laparoscopic technique and antibiotic prophylaxis. Indeed, analysis even revealed that the influence exerted by the endoscopic/laparoscopic technique on onset of postoperative infectious complications had a more preventive effect than that of antibiotic prophylaxis. Hence, the minimally invasive procedure for 
Table 3 Multivariable analysis of impaired wound healing in all patients with open and endoscopic inguinal hernia repair

\begin{tabular}{|c|c|c|c|c|c|}
\hline \multirow[t]{2}{*}{ Parameter } & \multirow[t]{2}{*}{$p$} & \multirow[t]{2}{*}{ Categories } & \multirow[t]{2}{*}{ OR estimate } & \multicolumn{2}{|l|}{$95 \% \mathrm{CI}$} \\
\hline & & & & Lower CL & Upper CL \\
\hline Operation technique & $<0.001$ & Laparoscopic versus open & 0.318 & 0.230 & 0.439 \\
\hline \multirow[t]{3}{*}{ ASA score } & \multirow[t]{3}{*}{$<0.001$} & II versus I & 0.750 & 0.524 & 1.073 \\
\hline & & III versus I & 1.301 & 0.795 & 2.129 \\
\hline & & IV versus I & 4.226 & 1.579 & 11.311 \\
\hline Sex & $<0.001$ & Male versus female & 0.531 & 0.369 & 0.764 \\
\hline Primary operation & 0.008 & Yes versus no & 0.601 & 0.412 & 0.876 \\
\hline Antibiotic prophylaxis & 0.021 & Yes versus no & 0.706 & 0.525 & 0.949 \\
\hline \multirow[t]{2}{*}{ Defect size } & \multirow[t]{2}{*}{0.107} & $\mathrm{I}(<1.5 \mathrm{~cm})$ versus III $(>3 \mathrm{~cm})$ & 0.618 & 0.387 & 0.984 \\
\hline & & II $(1.5-3 \mathrm{~cm})$ versus III $(>3 \mathrm{~cm})$ & 0.789 & 0.574 & 1.085 \\
\hline Age (10-year OR) & 0.331 & & 0.951 & 0.859 & 1.052 \\
\hline Risk factors & 0.707 & Yes versus no & 0.939 & 0.675 & 1.305 \\
\hline
\end{tabular}

Table 4 Multivariable analysis of deep infection in all patients with open and endoscopic inguinal hernia repair

\begin{tabular}{|c|c|c|c|c|c|}
\hline \multirow[t]{2}{*}{ Parameter } & \multirow[t]{2}{*}{$p$} & \multirow[t]{2}{*}{ Categories } & \multirow[t]{2}{*}{ OR estimate } & \multicolumn{2}{|l|}{$95 \% \mathrm{CI}$} \\
\hline & & & & Lower CL & Upper CL \\
\hline Operation technique & $<0.001$ & Laparoscopic versus open & 0.259 & 0.167 & 0.402 \\
\hline Antibiotic prophylaxis & 0.006 & Yes versus no & 0.593 & 0.408 & 0.862 \\
\hline \multirow[t]{3}{*}{ ASA score } & 0.008 & II versus I & 0.946 & 0.584 & 1.532 \\
\hline & & III versus I & 1.541 & 0.814 & 2.916 \\
\hline & & IV versus I & 5.425 & 1.732 & 16.992 \\
\hline \multirow[t]{2}{*}{ Defect size } & 0.229 & I $(<1.5 \mathrm{~cm})$ versus III $(>3 \mathrm{~cm})$ & 1.189 & 0.697 & 2.029 \\
\hline & & II $(1.5-3 \mathrm{~cm})$ versus III $(>3 \mathrm{~cm})$ & 0.795 & 0.524 & 1.206 \\
\hline Risk factors & 0.278 & Yes versus no & 1.250 & 0.835 & 1.873 \\
\hline Sex & 0.582 & Male versus female & 0.865 & 0.515 & 1.451 \\
\hline Primary operation & 0.756 & Yes versus no & 0.917 & 0.532 & 1.582 \\
\hline Age (10-year OR) & 0.871 & & 1.011 & 0.886 & 1.154 \\
\hline
\end{tabular}

Table 5 Multivariable analysis of impaired wound healing and deep infection in all patients with endoscopic inguinal hernia repair

\begin{tabular}{llll}
\hline & Impaired wound healing & Deep infection \\
\hline $\begin{array}{l}\text { Model fitting } \\
\text { (Global test) }\end{array}$ & $p$ & 0.6431 & 0.8409 \\
\hline
\end{tabular}

inguinal hernia repair made a greater contribution to the prevention of impaired wound healing and deep infections with mesh involvement than did antibiotic prophylaxis.

If one analyzes the group of 48,201 endoscopic/laparoscopic surgery patients as a separate entity, one notes that the use of antibiotic prophylaxis was unable to reduce further the rates of impaired wound healing and deep infections with mesh involvement. Hence, antibiotic prophylaxis should not be administered for endoscopic/laparoscopic inguinal hernia surgery. Conversely, analysis of the 36,832 open inguinal hernia repair group showed that antibiotic prophylaxis had a significant impact on onset of postoperative impaired wound healing and deep infections with mesh involvement. Accordingly, antibiotic prophylaxis should be administered for open inguinal hernia repair.

Of the 14 prospective randomized controlled trials that compared inguinal hernia surgery under antibiotic prophylaxis versus placebo, the endoscopic technique was performed only in one case trial [4]. However, due to methodological drawbacks that study was not taken into account in the Cochrane review [7]. 
Table 6 Multivariable analysis of impaired wound healing in all patients with open inguinal hernia repair

\begin{tabular}{|c|c|c|c|c|c|}
\hline \multirow[t]{2}{*}{ Parameter } & \multirow[t]{2}{*}{$p$} & \multirow[t]{2}{*}{ Categories } & \multirow[t]{2}{*}{ OR estimate } & \multicolumn{2}{|l|}{$95 \% \mathrm{CI}$} \\
\hline & & & & Lower CL & Upper CL \\
\hline \multirow[t]{3}{*}{ ASA score } & \multirow[t]{3}{*}{$<0.001$} & II versus I & 0.795 & 0.515 & 1.227 \\
\hline & & III versus I & 1.485 & 0.837 & 2.634 \\
\hline & & IV versus I & 5.106 & 1.836 & 14.200 \\
\hline Primary operation & 0.001 & Yes versus no & 0.512 & 0.339 & 0.774 \\
\hline Sex & 0.003 & Male versus female & 0.532 & 0.350 & 0.807 \\
\hline Antibiotic prophylaxis & 0.027 & Yes versus no & 0.677 & 0.479 & 0.958 \\
\hline \multirow[t]{2}{*}{ Defect size } & \multirow[t]{2}{*}{0.267} & I $(<1.5 \mathrm{~cm})$ versus III $(>3 \mathrm{~cm})$ & 0.646 & 0.377 & 1.109 \\
\hline & & II $(1.5-3 \mathrm{~cm})$ versus III $(>3 \mathrm{~cm})$ & 0.829 & 0.576 & 1.195 \\
\hline Age (10-year OR) & 0.446 & & 0.955 & 0.848 & 1.075 \\
\hline Risk factors & 0.532 & Yes versus no & 0.886 & 0.605 & 1.296 \\
\hline
\end{tabular}

Table 7 Multivariable analysis of deep infection in all patients with open inguinal hernia repair

\begin{tabular}{|c|c|c|c|c|c|}
\hline \multirow[t]{2}{*}{ Parameter } & \multirow[t]{2}{*}{$p$} & \multirow[t]{2}{*}{ Categories } & \multirow[t]{2}{*}{ OR estimate } & \multicolumn{2}{|l|}{$95 \% \mathrm{CI}$} \\
\hline & & & & Lower CL & Upper CL \\
\hline Antibiotic prophylaxis & 0.003 & Yes versus no & 0.522 & 0.341 & 0.798 \\
\hline \multirow[t]{3}{*}{ ASA score } & \multirow[t]{3}{*}{0.010} & II versus I & 0.900 & 0.507 & 1.597 \\
\hline & & III versus I & 1.539 & 0.744 & 3.181 \\
\hline & & IV versus I & 5.241 & 1.593 & 17.246 \\
\hline \multirow[t]{2}{*}{ Defect size } & \multirow[t]{2}{*}{0.024} & I $(<1.5 \mathrm{~cm})$ versus III $(>3 \mathrm{~cm})$ & 1.218 & 0.688 & 2.157 \\
\hline & & II $(1.5-3 \mathrm{~cm})$ versus III $(>3 \mathrm{~cm})$ & 0.601 & 0.375 & 0.962 \\
\hline Risk factors & 0.107 & Yes versus no & 1.454 & 0.922 & 2.292 \\
\hline Age (10-year OR) & 0.580 & & 1.044 & 0.897 & 1.216 \\
\hline Primary operation & 0.589 & Yes versus no & 0.850 & 0.470 & 1.535 \\
\hline Sex & 0.728 & Male versus female & 0.901 & 0.500 & 1.623 \\
\hline
\end{tabular}

Nor has the impact of antibiotic prophylaxis on occurrence of infectious complications following endoscopic/ laparoscopic inguinal hernia operations been investigated by other studies recorded in the review [1]. As such, the Guidelines of the European Hernia Society and the International Endohernia Society do not contain any clear-cut recommendations as to whether antibiotic prophylaxis should or should not be administered for endoscopic/laparoscopic inguinal hernia repair $[1,8]$. This present study by the Herniamed Registry has now clearly demonstrated for a large patient collective that antibiotic prophylaxis does not bestow additional benefits in the case of endoscopic/laparoscopic inguinal hernia surgery. The positive impact of the endoscopic/laparoscopic technique on avoidance of impaired wound healing and deep infections with mesh involvement is already so great that antibiotic prophylaxis has no additional benefit.
However, the converse situation applies for open inguinal hernia repair. Multivariable analysis identified that antibiotic prophylaxis had a significant effect on onset of impaired wound healing and deep infections with mesh involvement. That concords with the findings of several meta-analyses [9-12]. Conversely, the Cochrane review [7] and a systematic review and meta-analysis [13] concluded that antibiotic prophylaxis did not prevent the occurrence of wound infection after groin hernia surgery. In an update of Guidelines of the European Hernia Society [8], antibiotic prophylaxis is thus only recommended for high postoperative infection rates $(>5 \%)$. While the total rate of postoperative impaired wound healing and deep infections for open inguinal hernia surgery given in the Herniamed Registry is markedly lower than that, it has been possible to demonstrate the positive effect of antibiotic prophylaxis on the basis of a large patient collective. Accordingly, 
impaired wound healing would occur only in 31 rather than in 46 of every 10,000 cases. It would be possible to reduce almost by half the proportion of deep infections from 33 to 17 for every 10,000 operations. Therefore, antibiotic prophylaxis should be administered for open inguinal hernia surgical repair.

Acknowledgments Ferdinand Köckerling has got grants to fund the Herniamed Registry from Johnson \& Johnson, Norderstedt, Karl Storz, Tuttlingen, PFM Medical, Cologne, Dahlhausen, Cologne, B Braun, Tuttlingen, MenkeMed, Munich and BARD, Karlsruhe. Reinhard Bittner, Dietmar Jacob, Christine Schug-Pass, Christian Laurenz, Daniela Adolf, Thomas Keller and Bernd Stechemesser have no conflicts of interest or financial ties to disclose.

Open Access This article is distributed under the terms of the Creative Commons Attribution License which permits any use, distribution, and reproduction in any medium, provided the original author(s) and the source are credited.

\section{Appendix: Herniamed study group}

\section{Scientific board}

Köckerling, Ferdinand (Chairman); Berger, Dieter; Bittner, Reinhard; Fortelny, René; Koch, Andreas; Kraft, Barbara; Kuthe, Andreas; Lorenz, Ralph; Mayer, Franz; Moesta, Kurt Thomas; Niebuhr, Henning; Peiper, Christian; Pross, Matthias; Reinpold, Wolfgang; Simon, Thomas; Stechemesser, Bernd; Unger, Solveig

\section{Participants}

Ahmetov, Azat (Saint-Petersburg); Alapatt, Terence Francis (Frankfurt/Main); Anders, Stefan (Berlin); Anderson, Jürina (Würzburg); Arndt, Anatoli (Elmshorn); Asperger, Walter (Halle); Avram, Iulian (Saarbrücken); Barkus; Jörg (Velbert); Becker, Matthias (Freital); Behrend, Matthias (Deggendorf); Beuleke, Andrea (Burgwedel); Berger, Dieter (Baden-Baden); Bittner, Reinhard (Rottenburg); Blumberg, Claus (Lübeck); Böckmann, Ulrich (Papenburg); Böhle, Arnd Steffen (Bremen); Böttger, Thomas Carsten (Fürth); Borchert, Erika (Grevenbroich); Born, Henry (Leipzig); Brabender, Jan (Köln); Breitenbuch von, Philipp (Radebeul); Brüggemann, Armin (Kassel); Brütting, Alfred (Erlangen); Budzier, Eckhard (Meldorf); Burghardt, Jens (Rüdersdorf); Carus, Thomas (Bremen); Cejnar, Stephan-Alexander (München); Chirikov, Ruslan (Dorsten); Comman, Andreas (Bogen); Crescenti, Fabio (Verden/Aller); Dapunt, Emanuela (Bruneck); Decker, Georg (Berlin); Demmel, Michael (Arnsberg); Descloux, Alexandre (Baden); Deusch, Klaus-Peter (Wiesbaden); Dick, Marcus (Neumünster); Dieterich, Klaus (Ditzingen); Dietz, Harald (Landshut); Dittmann, Michael (Northeim); Dornbusch,
Jan (Herzberg/Elster); Drummer, Bernhard (Forchheim); Eckermann, Oliver (Luckenwalde); Eckhoff, Jörn /Hamburg); Elger, Karlheinz (Germersheim); Engelhardt, Thomas (Erfurt); Erichsen, Axel (Friedrichshafen); Eucker, Dietmar (Bruderholz); Fackeldey, Volker (Kitzingen); Farke, Stefan (Delmenhorst); Faust, Hendrik (Emden); Federmann, Georg (Seehausen); Feichter, Albert (Wien); Fiedler, Michael (Eisenberg); Fischer, Ines (Wiener Neustadt); Fortelny, René H. (Wien); Franczak, Andreas (Wien); Franke, Claus (Düsseldorf); Frankenberg von, Moritz (Salem); Frehner, Wolfgang (Ottobeuren); Friedhoff, Klaus (Andernach); Friedrich, Jürgen (Essen); Frings, Wolfram (Bonn); Fritsche, Ralf (Darmstadt); Frommhold, Klaus (Coesfeld); Frunder, Albrecht (Tübingen); Fuhrer, Günther (Reutlingen); Gassler, Harald (Villach); Gerdes, Martin (Ostercappeln); Gilg, KaiUwe (Hartmannsdorf); Glaubitz, Martin (Neumünster); Glutig, Holger (Meißen); Gmeiner, Dietmar (Bad Dürrnberg); Göring, Herbert (München); Grebe, Werner (Rheda-Wiedenbrück); Grothe, Dirk (Melle); Gürtler, Thomas (Zürich); Hache, Helmer (Löbau); Hämmerle, Alexander (Bad Pyrmont); Haffner, Eugen (Hamm); Hain, Hans-Jürgen (Groß-Umstadt); Hammans, Sebastian (Lingen); Hampe, Carsten (Garbsen); Harrer, Petra (Starnberg); Heinzmann, Bernd (Magdeburg); Heitland, Tim (München); Helbling, Christian (Rapperswil); Hempen, Hans-Günther (Cloppenburg); Henneking, Klaus-Wilhelm (Bayreuth); Hermes, Wolfgang (Weyhe); Herrgesell, Holger (Berlin); Herzing, Holger Höchstadt); Hessler, Christian (Bingen); Hildebrand, Christiaan (Langenfeld); Höferlin, Andreas (Mainz); Hoffmann, Michael (Kassel; Hofmann, Eva M. (Frankfurt/Main); Hopfer, Frank (Eggenfelden); Hornung, Frederic (Wolfratshausen); Hügel, Omar (Hannover); Hüttemann, Martin (Oberhausen); Huhn, Ulla (Berlin); Imdahl, Andreas (Heidenheim); Jacob, Dietmar (Bielefeld); Jenert, Burghard (Lichtenstein); Jugenheimer, Michael (Herrenberg); Junger, Marc (München); Käs, Stephan (Weiden); Kahraman, Orhan (Hamburg); Kaiser, Christian (Westerstede); Kaiser, Stefan (Kleinmachnow); Kapischke, Matthias (Hamburg); Karch, Matthias (Eichstätt); Keck, Heinrich (Wolfenbüttel); Keller, Hans W. (Bonn); Kienzle, Ulrich (Karlsruhe); Kipfmüller, Brigitte (Köthen); Kirsch, Ulrike (Oranienburg); Klammer, Frank (Ahlen); Klatt, Richard (Hagen); Kleemann, Nils (Perleberg); Klein, Karl-Hermann (Burbach); Kleist, Sven (Berlin); Klobusicky, Pavol (Bad Kissingen); Kneifel, Thomas (Datteln); Knoop, Michael (Frankfurt/Oder); Knotter, Bianca (Mannheim); Koch, Andreas (Cottbus); Köckerling, Ferdinand (Berlin); Köhler, Gernot (Linz); König, Oliver (Buchholz); Kornblum, Hans (Tübingen); Krämer, Dirk (Bad Zwischenahn); Kraft, Barbara (Stuttgart); Kreissl, Peter (Ebersberg); Krones, Carsten Johannes (Aachen); Kruse, 
Christinan (Aschaffenburg); Kube, Rainer (Cottbus); Kühlberg, Thomas (Berlin); Kuhn, Roger (Gifhorn); Kusch, Eduard (Gütersloh); Kuthe, Andreas (Hannover); Ladberg, Ralf (Bremen); Ladra, Jürgen (Düren); LahrEigen, Rolf (Potsdam); Lainka, Martin (Wattenscheid); Lammers, Bernhard J. (Neuss); Lancee, Steffen (Alsfeld); Larusson, Hannes Jon (Pinneberg); Lauschke, Holger (Duisburg); Leher, Markus (Schärding); Leidl, Stefan (Waidhofen/Ybbs); Lenz, Stefan (Berlin); Lesch, Alexander (Kamp-Lintfort); Lienert, Mark (Duisburg); Limberger, Andreas (Schrobenhausen); Locher, Martin (Kiel); Loghmanieh, Siawasch (Viersen); Lorenz, Ralph (Berlin); Mallmann, Bernhard (Krefeld); Manger, Regina (Schwabmünchen); Maurer, Stephan (Münster); Mayer, Franz (Salzburg); Menzel, Ingo (Weimar); Meurer, Kirsten (Bochum); Meyer, Moritz (Ahaus); Mirow, Lutz (Kirchberg); Mittenzwey, Hans-Joachim (Berlin); MörderKöttgen, Anja (Freiburg); Moesta, Kurt Thomas (Hannover); Moldenhauer, Ingolf (Braunschweig); Morkramer, Rolf (Xanten); Mosa, Tawfik (Merseburg); Müller, Hannes (Schlanders); Münzberg, Gregor (Berlin); Mussack, Thomas (St. Gallen); Neumann, Jürgen (Haan); Niebuhr, Henning (Hamburg); Nölling, Anke (Burbach); Nostitz, Friedrich Zoltán (Mühlhausen); Obermaier, Straubing); Öz-Schmidt, Meryem (Hanau); Oldorf, Peter (Usingen); Olivieri, Manuel (Pforzheim); Pawelzik, Marek (Hamburg); Peiper, Christian (Hamm); Pertl, Alexander (Spittal/Drau); Philipp, Mark (Rostock); Pickart, Lutz (Bad Langensalza); Pizzera, Christian (Graz); Pöllath, Martin (Sulzbach-Rosenberg); Possin, Ulrich (Laatzen); Prenzel, Klaus (Bad Neuenahr-Ahrweiler); Pröve, Florian (Goslar); Pronnet, Thomas (Fürstenfeldbruck); Pross, Matthias (Berlin); Puff, Johannes (Dinkelsbühl); Rabl, Anton (Passau); Rapp, Martin (Neunkirchen); Reck, Thomas (Püttlingen); Reinpold, Wolfgang (Hamburg); Reuter, Christoph (Quakenbrück); Richter, Jörg (Winnenden); Riemann, Kerstin (AlzenauWasserlos); Rodehorst, Anette (Otterndorf); Roehr, Thomas (Rödental); Roncossek, Bremerhaven); Roth Hartmut (Nürnberg); Sardoschau, Nihad (Saarbrücken); Sauer, Gottfried (Rüsselsheim); Sauer, Jörg (Arnsberg); Seekamp, Axel (Freiburg); Seelig, Matthias (Bad Soden); Seiler, Christoph Michael (Warendorf); Seltmann, Cornelia (Hachenburg); Senkal, Metin (Witten); Shamiyeh, Andreas (Linz); Shang, Edward (München); Siemssen, Björn (Berlin); Sievers, Dörte (Hamburg); Silbernik, Daniel (Bonn); Simon, Thomas (Sinsheim); Sinn, Daniel (Olpe); Sinning, Frank (Nürnberg); Smaxwil, Constatin Aurel (Stuttgart); Schabel, Volker (Kirchheim/Teck); Schadd, Peter (Euskirchen); Schassen von, Christian (Hamburg); Schattenhofer, Thomas (Vilshofen); Scheidbach, Hubert (Neustadt/Saale); Schelp, Lothar (Wuppertal); Scherf, Alexander (Pforzheim); Scheyer, Mathias
(Bludenz); Schimmelpenning, Hendrik (Neustadt in Holstein); Schinkel, Svenja (Kempten); Schmid, Michael (Gera); Schmid, Thomas (Innsbruck); Schmidt, Rainer (Paderborn); Schmidt, Sven-Christian (Berlin); Schmidt, Ulf (Mechernich); Schmitz, Heiner (Jena); Schmitz, Ronald (Altenburg); Schöche, Jan (Borna); Schoenen, Detlef (Schwandorf); Schrittwieser, Rudolf /Bruck an der Mur); Schroll, Andreas (München); Schultz, Christian (Bremen-Lesum); Schultz, Harald (Landstuhl); Schulze, Frank P. Mülheim an der Ruhr); Schumacher, Franz-Josef (Oberhausen); Schwab, Robert (Koblenz); Schwandner, Thilo (Lich); Schwarz, Jochen Günter (Rottenburg); Schymatzek, Ulrich (Radevormwald); Spangenberger, Wolfgang (Bergisch-Gladbach); Sperling, Peter (Montabaur); Staade, Katja (Düsseldorf); Staib, Ludger (Esslingen); Stamm, Ingrid (Heppenheim); Stark, Wolfgang (Roth); Stechemesser, Bernd (Köln); Steinhilper, Uz (München); Stern, Oliver (Hamburg); Stolte, Thomas (Mannheim); Stopinski, Jürgen (Schwalmstadt); Stubbe, Hendrik (Güstrow/); Stülzebach, Carsten (Friedrichroda); Tepel, Jürgen (Osnabrück); Terzić, Alexander (Wildeshausen); Teske, Ulrich (Essen); Thews, Andreas (Schönebeck); Tillenburg, Wolfgang (Marktheidenfeld); Timmermann, Wolfgang (Hagen); Train, Stefan H. (Gronau); Trauzettel, Uwe (Plettenberg); Triechelt, Uwe (Langenhagen); Ulcar, Heimo (Schwarzach im Pongau); Unger, Solveig (Chemnitz); Verweel, Rainer (Hürth); Vogel, Ulrike (Berlin); Voigt, Rigo (Altenburg); Voit, Gerhard (Fürth); Volkers, Hans-Uwe (Norden); Vossough, Alexander (Neuss); Wallasch, Andreas (Menden); Wallner, Axel (Lüdinghausen); Warscher, Manfred (Lienz); Warwas, Markus (Bonn); Weber, Jörg (Köln); Weiß, Johannes (Schwetzingen); Weißenbach, Peter (Neunkirchen); Werner, Uwe (Lübbecke-Rahden); Wessel, Ina (Duisburg); Weyhe, Dirk (Oldenburg); Wieber, Isabell (Köln); Wiesmann, Aloys (Rheine); Wiesner, Ingo (Halle); Woehe, Fritz (Sanderhausen); Wolf, Claudio (Neuwied); Yildirim, Selcuk (Berlin); Zarras, Konstantinos (Düsseldorf); Zeller, Johannes (Waldshut-Tiengen); Zhorzel, Sven (Agatharied); Zuz, Gerhard (Leipzig);

\section{References}

1. Bittner R, Arregui ME, Bisgaard T, Dudai M, Ferzli GS, Fitzgibbons RJ, Fortelny RH, Klinge U, Koeckerling F, Kuhry E, Kukleta J, Lomanto D, Misra MC, Montgomery A, MoralesCondes S, Reinpold W, Rosenberg J, Sauerland S, Schug-Pass C, Singh K, Timoney M, Weyhe D, Chowbey P (2011) Guidelines for laparoscopic (TAPP) and endoscopic (TEP) treatment of inguinal hernia [International Endohernia Society (IEHS)]. Surg Endosc 25(9):2773-2843. doi:10.1007/s00464-011-1799-6

2. Bittner R, Schmedt CG, Schwarz J, Kraft K, Leible BJ (2002) Laparoscopic transperitoneal procedure for routine repair of groin hernia. Br J Surg 89(8):1062-1066 
3. Tamme C, Scheidbach H, Hampe C, Schneider C, Köckerling F (2003) Totally extraperitoneal endoscopic inguinal hernia repair (TEP). Surg Endosc 17:190-195. doi:10.1007/s00464-002-89058

4. Schwetling R, Bärlehner E (1998) Is there an indication for general perioperative antibiotic prophylaxis in laparoscopic plastic hernia repair with implantation of alloplastic tissue? Zentralbl Chir 123(2):193-195

5. Stechemesser B, Jacob DA, Schug-Paß C, Köckerling F (2012) Herniamed: an internet-based registry for outcome research in hernia surgery. Hernia 16(3):269-276. doi:10.1007/s10029-0120908-3

6. Wacha H, Hyome U, Isenmann R, Kujath P, Lebert C, Naber K, Salzberger B (2010) Perioperative antibiotika-prophylaxe. Chemother J 19:70-84

7. Sanchez-Manuel FJ, Lozano-Garcia J, Seco-Gil JL (2012) Antibiotic prophylaxis for hernia repair. Cochrane Database Syst Rev 15(2):CD003769. doi:10.1002/14651858.CD003769.pub4

8. Miserez M, Peeters E, Aufenacker T, Bouillot JL, Campanelli G, Conze J, Fortelny R, Heikkinen T, Jorgensen LN, Kukleta J, Morales-Conde S, Nordin P, Schumpelck V, Smedberg S, Smietanski M, Weber G, Simons MP (2014) Update with level 1 studies of the European Hernia Society guidelines on the treatment of inguinal hernia in adult patients. Hernia 18:151-163

9. Sanabria A, Dominguez LC, Valdivieso E, Gómez G (2007) Prophylactic antibiotics for mesh inguinal hernioplasty. Ann Surg 245(3):392-396

10. Li JF, Lai DD, Zhang XD, Zhang AM, Sun KX, Luo HG, Yu Z (2012) Meta-analysis of the effectiveness of prophylactic antibiotics in the prevention of postoperative complications after tension-free hernioplasty. Can J Surg 55(1):27-32

11. Yin YY, Song T, Liao B, Luo Q, Zhou Z (2012) Antibiotic prophylaxis in patients undergoing open mesh repair of inguinal hernia: a meta-analysis. Am Surg 78(3):359-365

12. Mazaki T, Mado K, Masuda H, Shiono M (2013) Antibiotic prophylaxis for the prevention of surgical site infection after tension-free hernia repair: a Bayesian and frequentist meta-analysis. J Am Coll Surg 217(5):788-801. doi:10.1016/j.jamcollsurg. 2013.07.386

13. Aufenacker TJ, Koelemay MJW, Gouma DJ, Simons MP (2006) Systematic review and meta-analysis of the effectiveness of antibiotic prophylaxis in prevention of wound infection after mesh repair of abdominal wall hernia. Br J Surg 93:5-10 